\title{
Reconciliation as a Woman-Centered Response to Intimate Partner Violence
}

\author{
Kelsi Toews*
}

\begin{abstract}
Intimate partner violence (IPV) is a serious and prevalent issue throughout the world (Devries et al. 2013, 1527). IPV takes place within an intersectional context that includes race, gender, culture, power, and sexuality. The types of actions taken to combat this violence vary greatly between different cultural contexts. The United States and Canada frequently take a lawbased approach toward dealing with perpetrators and attempt to assist the victims through various social service sectors. Countries of reconciliation, such as Senegal, Trinidad and Tobago, and Kazakhstan, where individuals wish to keep the issue in the private sphere, often employ an approach aimed at maintaining the family system. Acts of reconciliation as a response to IPV have been deemed as an inappropriate and oppressive reaction to the violence perpetuated against the victims (Coker, 2002; London, 1997). However, this criticism neglects the clear intersection of IPV responses and cultural contexts, thereby neglecting the autonomy of the woman to choose the response she believes most aligns with her cultural values. Through its emphasis on family, hospitality, respect, as well as religious texts and parables, the Society of Muslim Women (SMW) in Kazakhstan provides an example of a culturally and gender-appropriate reconciliation process. With the example of Kazakhstan, this paper shows that the reconciliation approach can allow the autonomy and cultural values of the female victim to be appreciated.
\end{abstract}

Keywords: Intimate Partner Violence, Reconciliation, Gender, Violence, Cross-Culture

Intimate partner violence (IPV), a serious and prevalent issue throughout the world (Devries et al. 2013, 1527) that is characterized by "acts of violence, power, and coercion intended to control another's behavior" and can include actions of physical, sexual, emotional, economic, and psychological abuse (Nevada Attorney General, 2011). Current definitions of IPV, such as acts of violence of numerous forms perpetrated against an intimate partner, either former or current (Nevada Attorney General 2011, 5) have evolved, and now use gender-inclusive or genderneutral language to attend to the increasing awareness of the multifaceted nature of IPV, which occurs within all social and sexual groups (Du Plat-Jones 2006; Hester \& Westmarland, 2005). However, it is important to recognize that there are nuances among the different relationships in which IPV may occur, and thus it is important specify the details of the partnership. These nuances, coupled with the high prevalence of IPV against women in heterosexual relationships (16.3\% to65.6\%; Devries et al. 2013, 1528), provide the focus of this paper, on female victims of IPV in heterosexual relationships. IPV further takes place within an intersectional context, and thus the actions taken to

*Department of Psychology, College of Arts and Science, University of Saskatchewan, Saskatoon, SK, Canada

Correspondence: ket457@mail.usask.ca 
combat this violence may vary among cultural contexts. Approaches include those based on social service sector provisions (e.g. U.S. and Canada), and reconciliatory approaches, aimed at maintaining the family unit (e.g. Senegal, Trinidad and Tobago, and Kazakhstan). This reconciliatory approach can be applied in an inappropriate and oppressive manner (Coker, 2002; London, 1997). However, applying this view to all areas that utilize reconciliatory approaches to IPV neglects the intersection of IPV responses with culture, thereby neglecting the autonomy of an abused woman to choose the response that she deems best aligns with her cultural values. An example of where reconciliation is applied in a culturally- and gender-appropriate way is the services which Kazakhstan's Society of Muslim Women (SMW) provide. By using the example of Kazakhstan, I argue that the reconciliation approach can be a culturally-appropriate and womancentered approach to IPV, allowing for an appreciation of both the autonomy and cultural values of the victim.

Both the action of and responses to IPV are best understood when viewed through an intersectional framework. Intersectional frameworks concentrate on the experiences of groups which hold multiple disadvantaged statuses (Cole and Sabik 2009). One example is can be found in gender roles and sexuality, which, independently, might be limited because individuals experience these positions simultaneously (Cole and Sabik 2009). Mann (2000) provides a further overview of this concept, writing, "Within gender studies, the race, class, gender analysis is known by different names... By any of these names, its focus on multiple oppressions and difference has been its hallmark" (Mann 2000, 477). The guiding principle of an intersectional analysis is its focus on the concurrent, numerous, and intertwining oppressions of people (Mann and Grimes 2001, 8). Bogran (1999) suggests that IPV is not an isolated phenomenon and that intersectionality paints the meaning and nature of IPV, including how it is experienced by the individual; how others respond to it; how the personal and social consequences are represented; and how, or if, assistance and safety can be achieved (276).

Within race, culture, and sexuality individuals may have personal ideologies and constraints which determine how, and if, they disclose violent situations (Bogran 1999, 281). We see an example of this in Vietnamese women who are taught that protecting their reputation and family unity is more important than escaping possible abuse (Schuler et al. 2014). This may lead victims to pursue a more private, mediatory, or conciliatory process to deal with the abuse. Individuals may be unwilling to report to the police for fear of racist treatment by the criminal justice system, and of confirming stereotypes surrounding their race (Richie 2000). Also contributing to the intersectional nature of IPV is the individual's class. Much research has been conducted suggesting that IPV occurs in astounding rates among low- income women, especially low-income women of colour (Rennison and Planty 2003; Tolman and Raphael 2000; West 2004, 2005). Further intersections with homosexuality occur, such that fear of homonegativity from social service sectors and other institutions may prevent victims of IPV in homosexual relationships from leaving the abusive relationships (Pattavina et al. 2007). Their partner may also hold great power in threatening the victim with "outing" them, or threatening to inform others that the victim is gay or lesbian, which may stop the victim from seeking help, or instead pursuing a reconciliation process, over calling the police (Rohrbaugh 2006). Thus, IPV is not a result of isolated gender oppression, but is manifested in and exacerbated by a variety of intersecting issues.

Responses to IPV vary per the cultural context. Snadjr discusses the necessity of "balancing political relationships among stakeholders, and performing the problems of and solutions to [IPV] within national discourses and local bureaucracies" (Snadjr 2010, 114). In Western countries such as Canada and the United States, judicial and law-based responses where the victim is separated from her abuser are prevalent (Koss 2000, 1335). Specifically, in 1983. these countries implemented a proarrest or mandatory-arrest policy to combat the occurrence of IPV (Chewter 2003, 103). This policy requires police officers to arrest the person whom the police deem the primary aggressor (Chewter 2003, 106). In addition to these judicial responses, in Canada and the U.S. there are various government funded shelters and psychological services offered to victims of IPV. Wies (2011) specifically discusses a United States anti-domestic violence coalition that included a plethora of social service sectors, as the coalition believes that "domestic violence cannot be properly addressed unless a community of persons act - no one group can do it alone" (Hassler 1995, 199). Through an ethnographic account of the lived experiences of both the workers and the victims, Wies (2011) portrays the efficacy of this specific treatment program; it draws from various facets of assistance, and provides the victim with a safe house from her abuser, as well as with counselling services, legal advocacy, and access to a lawyer, support groups, and a caseworker (Wies 2011, 68). These provisions might allow for women's autonomy through allowing for a preservation of their personal choice. There have also been attempts in North America towards dispute resolution and restorative initiatives. Examples such as restorative justice and Navajo peacemaking within American Indian populations (Coker 2006), as well as restorative justice initiatives (Kohn 2010) and mediation/family dispute resolution (Rimelspach 2001) have also been employed within broader North American society. These responses, similar to reconciliatory approaches, are not without critique, and researchers have questioned their role in harmfully re-privatizing IPV, and 
privileging family and community forms of insight that may not be helpful to the IPV victim (Acorn 2004; Coker 2002)

Restorative justice, or the reconciliatory process, is more predominant in collectivist countries. This paper examples the examples of Trinidad and Tobago, Senegal, and Kazakhstan (Lazarus-Black 2001; London 1997; Snadjr 2005, 2010). The act of reconciliation "involves the formation or restoration of genuine peaceful relationships between [persons]" (Bar-Tal 2009, 365). Lazarus-Black talks of 'cultures of reconciliation,' and she recognizes that in these areas, such as in Trinidad, a powerful culture of reconciliation shapes the law, which reflects how Trinidadians perceive family and relationships $(2007,156)$. Specifically, a culture of reconciliation may reflect practices and customs that are fundamental to family, gender, and work, and that intersect to keep individuals out of legal procedures and uphold considerations of obligations and responsibilities to family members (Lazarus-Black 2008). Ricoeur (1999) further describes a culture of reconciliation as a culture that can transform conflict to the level of discourse and not let disagreements deteriorate into violence. Other definitions describe a culture of reconciliation as a strategy of working to recall and learn from the past, with the intention of reconciling with one another (Goodwin 2007). With regards to IPV specifically, a culture of reconciliation operates under the mandate that "husband-wife business is 'private business,' that public attention to family quarrels is unsavory, that families should remain stable, that women should turn the other cheek for the sake of their children ... [and] that every effort should be made to resolve family disputes by reconciliation rather than by formal legal redress" (Lazarus-Black 2007:156). Generally, a family member, or a range of people in the community, conducts the reconciliation interventions (London 1997, 86). Intermediaries typically talk to each party separately, hoping to resolve the problem before bringing the partners together (London 1997, 87). If this is unsuccessful, the couple is brought together, and numerous joint sessions are held (London 1997, 87). While the exact content of the reconciliation conversations varies, the main objective of the process is almost always to keep the couple together (London 1997, 87).

There is no denying that the reconciliation process can operate in a patriarchal and oppressive way, and can further take away the rights of the woman (London 1997; Lazarus-Black 2001, 2008; United Nations Committee on the Elimination of Discrimination against Women 1993). Coke (2002) noted that people may deem the reconciliation process oppressive, especially when examining the intersections of gender, patriarchy, and power dynamics within these families. London's (1997) fieldwork is an example of this. London (1997) examined the role of reconciliation in IPV disputes in Senegal, West Africa, an officially secular nation, but with a Muslim majority of $95 \%$.
This work included interviews with 100 disputants and thirdparty mediators, as well as observations of the reconciliation sessions and analyses of court documents. London used fieldwork to produce arguments against the reconciliation process that is dominant in IPV cases. According to London, the reconciliation process in Trinidad and Tobago marginalizes and trivializes violence, while subsequently appearing to provide a forum that addresses it, and in this way, enables the social control of women (London 1997, 83).

London states that reconciliation posits all problems as potential areas for negotiation, but does not consider the differences in positions of power that the disputants hold (1997, 83). Economic factors often prevent the women in Trinidad and Tobago from leaving violent husbands (London 1997, 85). In terms of power, many women are solely reliant on their husbands for economic support for themselves and their children, and thus men can perform acts of violence against them without concern for potential consequences, such as divorce London 1997, 85). Thus, the wife's involvement in the reconciliation process may be out of necessity and due to the economic domination of their husbands over them, rather than an autonomous choice to keep the family together. Moreover, in areas such as Trinidad and Tobago, the reconciliation process predominantly operates in a patriarchal context, with older males frequently being the ones leading the mediation sessions (London 1997, 86). In terms of gender intersections, many abusive husbands use the idea that women are "perpetually in danger of becoming disobedient and irresponsible" (London 1997, 84) to rationalize their violence (London 1997, 84). Therefore, because the reconciliation processes frequently begin with the premise that some level of violence is acceptable, this can direct the reconciliation process towards scrutinizing the woman's behavior to decide if the abuse was warranted (London 1997, 83). Furthermore, a reconciliatory approach to IPV can be viewed as an effort to keep this violence within the private sphere, an attempt which may be construed as opposing the critical efforts of feminists to gain public resources and criminal justice responses for these victims (Coker 2002).

Despite the ways in which the reconciliation process can be patriarchal and oppressive, I argue that viewing it as solely oppressive and sexist is ethnocentric, as it does not consider the cultural context in which the reconciliation process is used. Specifically, in many Muslim communities, the reconciliatory process may be appropriately applied to both keep the woman safe and to keep her values intact. One of the most prevalent features of Muslim societies is the emphasis on attachment to family (Dhami 2000, 352). The family unit is valued as the foundation of a healthy and stable society (Doi 1984). For example, Hassouneh-Philips (2001) performed a study 
looking at Muslim women's perceptions of family and their experiences of wife abuse. Participants in the study viewed marriage as a "means toward personal and spiritual fulfillment (Hassouneh-Phillips 2001, 932) and frequently quoted a common hadith (a quote from the prophet Mohammad), which states, "Marriage is half of the faith and the rest is fear Allah" (Hassouneh-Phillips 2001, 932). The belief that life-long marriage is a fulfillment of $50 \%$ of their responsibility toward God is imperative in understanding women's beliefs surrounding responses to IPV. For this reason, divorce or judicial approaches to resolving IPV often are not considered as options. Thus, IPV must be approached in a way that aims to keep the family system intact, as it is likely that many women place their religious faith at the forefront of their priorities.

An excellent example of the potentially appropriate application of this reconciliatory process is in Kazakhstan, an area that considers itself traditionally Muslim (Snadjr 2005). Kazakhstan went many years without formal laws or services for IPV perpetrators and victims. Movements towards addressing this issue were initially started by various grassroots programs addressing women's rights, such as the Feminist League, the Women's Information Network, the Association of Single Mothers, and the International Ecological Association of Women of the Orient (Snadjr 2010, 117). Following from these organizations' influence, in the late 1990 a female activism group called "Prodrugi" began its work towards addressing IPV issues in Kazakhstan, and opened the first IPV shelter in the country in 1999 (Snadjr 2010). During this time, next to no services were available for women suffering from IPV (Snadjr 2010).Police were responsible for the safety of these women, but provided little assistance (Snadjr 2010). Shortly after 1999, the government joined the battle against IPV and began developing IPV units in police departments across the country (Snadjr 2010). However, the officers in these units were undertrained, and the justice system remained complacent in that their punishments often involved relatively small fines for the perpetrators (Snadjr 2010). The Prodrugi continued to raise awareness for IPV and worked towards engaging with the police, training them, and giving presentations to people across the country (Snadjr 2010).

Kazakhstan currently has twenty IPV crisis centers, although seven of these are supported by the government and will only admit survivors if they have reported to the police (Human Rights Council 2010). Rates of IPV in Kazakhstan are difficult to ascertain. considering the hesitancy to report instances to the police. A 2007 report found that at least $52 \%$ of Kazakh women had been victimized by IPV (Bureau of Democracy, Human Rights, and Labor 2007) and further reports suggest numbers are as high as 70\% (UNIFEM 2005). (National Commission on Gender, Family and Demography Policy 2016). Local Non-
Governmental Organizations (NGOs) and the U.S. State Department suggest that actual levels of IPV in Kazakhstan far exceed these reported incidents (Bureau of Democracy, Human Rights, and Labor 2007). Further statistics show that police annually register over 10,000 IPV incidents, and that approximately 500 women die annually because of domestic conflicts (Bureau of Democracy, Human Rights, and Labor 2010). However, local NGOs suggest that $40 \%$ of IPV crimes go unreported (Bureau of Democracy, Human Rights, and Labor 2010). This discrepancy depicts the need for services for these women who are not reporting IPV instances to the authorities.

Attempts at ameliorating IPV in Kazakhstan are integrations of both private and public sector responses, and it is important to note that both operate within the context of police action and a criminal code. In 2009 the Kazakhstan government signed a new law on IPV, defining for the first time "domestic violence" and "victim;" identifying multiple types of violence, such as physical, psychological, sexual, and economic; and prescribing responsibilities of the local and national governments and NGOs in providing support to domestic violence victims (Bureau of Democracy, Human Rights, and Labor 2010). This law also outlines ways to ensure the issuance of restraining orders, and it allows for the administrative detention of perpetrators for 24 hours (Bureau of Democracy, Human Rights, and Labor 2010). Further, the criminal procedure code sets the maximum sentence for IPV at ten years in prison (Bureau of Democracy, Human Rights, and Labor 2010). However, tangible action by the government to promote changes in attitudes towards IPV and victim support is thought to be missing (UN Human Rights Council 2010; Bassiuoni ND). Furthermore, law enforcement only intervenes in IPV matters when the situation is deemed life-threatening (Bassiuoni ND). An example of this is found in Snadjr's (2007) research, which utilized training workshops and interviews with police in Kazakhstan. These police officers related the difficulties that arise when enforcing law based responses to what is commonly thought of as a private issue (Snadjr 2007). One police officer explained that for Kazakhs, interfering in the personal affairs of others is a form of disrespect, as well as a threat to one's own social standing. She further pointed out that people's ignoring of instances of IPV did not indicate a neglectful community, but rather maintenance of ethnic norms of social respect. Other officers agreed, and noted that this pillar of family privacy is likely to discourage victims from reporting violence to police. Additionally, they noted family privacy as a major obstacle in their attempts to gain accurate information about, as well as to make cases against, IPV perpetrators in Kazakhstan. This struggle of the law enforcement sector to properly implement IPV laws, and the aforementioned rates of unreported IPV 
instances, presents a picture of IPV responses which may not be culturally appropriate for some victims.

A potential answer to this call for more culturally aligned responses is found in the Society for Muslim Women's (SMW) response to IPV in Kazakhstan (Snadjr 2005). For these women, making the private issue of IPV a concern of a public response was unacceptable (Snadjr 2005 , 294). Consequently, the SMW was developed. The society provides numerous services to victims of IPV, such as leading reconciliatory mediation with the couple, as well as providing the victim with temporary shelter within the context of a Muslim culture. This includes the SMW activists welcoming women into their homes, and describing the sheltering as following Kazakh traditions of hospitality and obligation to one's guest. The SMW also provides confidentiality to protect the private sphere, as well as psychological counselling to assist the victims and to recognize the horrific abuse that occurred. Thus, the women in this area work outside of the criminal justice system while operating within a framework of reconciliation. They are noted as having emerged within a Muslim-oriented women's movement that is unwilling to cooperate either with the movements led by the aforementioned Prodrugi, or with the local police. This issue of the private versus public sphere differs between the Western and the Eastern countries, and it is important to note that beliefs surrounding the public and private spheres play a large role in countries' responses to IPV.

The SMW's methods of mediation are based on the Kazakh and Muslim women's beliefs that family is the cornerstone and most valued aspect of society (Snadjr 2005,300 ). Whether victims of violence or not, women are judged based on their functions as wives and mothers, and therefore are held accountable by relatives and neighbors for upholding family peace (Snadjr 2005, 297). The idea of the organization is to support a strong family; thus, they almost exclusively advise against divorce (Sadjr 2005, 300). They also ensure that they are available to both the husband and the wife, and further include input from the community and elders. If the elders conclude that the man is at fault, then he is shamed in front of his whole family (Snadjr 2005, 301). This further provides insight into the importance of family in this culture, such that being shamed in front of them is one of the greatest forms of punishment.

When the SMW activists engage with women during a reconciliation session, they use the proper terms of respect, adhere to values of hospitality, and understand the importance of family roles. Activists use the term "hanum" as a form of politeness and respect when speaking to victims who are older than the speaker (Snadjr 2005, 302). In order to uphold their cultural traditions, SMW activists situate the act of sheltering women from their abusers for a period of time as one of simply adhering to Kazakh traditions of showing hospitality to one's guests, rather than as helping women leave their husbands. (Snadjr $2005,303)$. They also speak to the women victims coming to them according to their roles in the family, addressing them as wives, mothers, or daughter in-laws, and not solely as victims (Snadjr 2005, 302). By doing this, they maintain the woman's identity as a member of the community, and honour the woman's authority in the context of those roles (Snadjr 2005, 302-303). The SMW also recognizes a woman's identity as a mother or desire to be a good wife by encouraging the reconciliation process, as when these roles break down (such as from police action or divorce), the women may be further isolated and blamed (Snadjr 2005, 303).

Throughout the reconciliation process, SMW activists approach IPV in a culturally appropriate way by reprimanding and critiquing male violence. They do this by adhering to and quoting religious texts and parables, such as: "Women were created to be gentle and pretty. God created them after man, because men are close to the Earth, close to the ground" (Snadjr 2005, 303). Through this, they work to challenge the abuser to demonstrate their authority, not through violence, but through their positions as husbands and father (Snadjr 2005, 303). When speaking with victims and/or abusers, the SMW activists draw from Muslim beliefs surrounding familial commitment and gender equality (Snadjr 2005, 303). As part of their counselling, SMW activists insistently argue that the divine teachings do not support wife abuse (Snadjr 2005, 303). The activists situate the acts of violence in a context of fight for cultural survival (i.e. from a history of Soviet rule), and use a discourse of ethnic struggle and preservation to reduce the blame against the victims (Snadjr 2005, 303). When the SWM situate the tragedy of IPV as one that could destroy their Kazakh culture and identity by deviating from its values regarding women, they cause the abusers to view their actions as a product of Soviet colonialism (Snadjr 2005, 303).

More recent research by Snadjr (2010) notes that there are women's NGOs working to combat IPV in Kazakhstan. As mentioned previously, organizations such as the Prodrugi, the Feminist League, and the Women's Information Centre are collaborating with the state to address IPV. However, Snadjr (2010) notes that the SMW is operating outside of, and is not willing to cooperate with, these organizations. This is due to the SMW's conceptualization that state and feminist-oriented NGOs are not acting in the best interest of the Kazakh religious and ethnic community (Snadjr 2010, 129).

Although there has been limited research into programs like the SMW in other Muslim countries, similar attitudes towards maintaining family honour, reconciliation, and ensuring privacy following IPV can be found. For example, in India, a variety of interventions exist to support women experiencing IPV (Snell-Rood 2015) 
including family courts, where women can present complaints about neglect and violence without a lawyer (Basu 2012), as well as mahila mandals/panchayats (women's councils), often located within NGOs, where lowincome women can present marital disputes to be heard by a council of local women (Snell-Rood 2015). In Israel, HajYahia (2002) researched Israeli women's opinions regarding IPV and found that these women believed that seeking help should begin within the family, that cultural norms should still be upheld, and that the process of coping with abuse should adhere to cultural values, family privacy, and discretion (through keeping the act of violence outside of the public eye). In Jordan, Btoush and Haj-Yahia (2008) investigated attitudes towards wife abuse. They found a strong tendency among participants to consider IPV a personal and familial issue, rather than one that was social and legal. The preferred method for dealing with IPV in this area was resorting to informal agents (e.g., family, community, or religious figures), and only in cases of repeated abuse and severe violence did they desire utilization of formal measures such as counselling and the legal system.

Despite the SMW's impressive efforts in combatting IPV in Kazakhstan, it is unclear whether the SMW's method of keeping IPV in the private sphere decreases rates of IPV, or ameliorates the critiques of reconciliatory processes. This is because maintaining privacy around IPV means that instances may not be reported or documented, and therefore decreases (or increases) in IPV-rates are not fully seen. However, acceptance levels of IPV in Kazakhstan have been falling, from 32\% in 1999, to 12\% in 2017 (Joshi and Childress 2017, 19), which may be due to an amalgamation of the recent IPV laws, NGO and government work, as well as the SMW's efforts. The question, however, may not be whether that dealing with IPV within the private sphere decreases the rates or acceptance of violence, but whether reconciliation is the method that aligns most closely with the methods that these survivors wish to utilize. If women refuse to report or seek public services for the IPV that they experience, alternative options must be presented. Interventions for IPV must respect desires to reconcile with perpetrators, and to maintain familial cohesion; meeting women where they are at -- socially, culturally, and religiously -- is important to working towards providing services to victims and towards eradicating IPV in the future. I believe that the SMW present such an option. The best practice methods for responding to IPV will differ per the individual, and what is the best practice for one woman, may not be so for another.

It is clear from a review of the literature that there are various intersections of culture, gender, race, and class included in the act of IPV, and in responses to IPV. Because of these intersections, it is important to understand that there are differing values, cultures, and beliefs that surround IPV. These differences in context mean that there can be a variety of responses and attempts to ameliorate or eradicate IPV. However, these responses will work better and be better received in certain countries, and within certain women's experiences, than others. The reconciliatory process is one such response, and its impact and efficacy in the country of Kazakhstan is contrary to the controversy surrounding it. The SMW's emphasis on family, hospitality, respect, and religious texts and parables during the reconciliation process allows this process to assist women victims of IPV in an efficient, culturally appropriate way. An anthropological view of intersectionality and cultural context and values shows that the reconciliatory process, such as the one in Kazakhstan, can be a womancentered approach to IPV that takes both the women's status as victims, and their desire to uphold their values and beliefs, into consideration. 


\section{References}

Acorn, Annalise E. 2004. Compulsory Compassion: A Critique of Restorative Justice. UBC Press.

Bassiuoni, Sarah N.D. Briefing note on the situation of women in central Asia: Working Paper. Division for Gender equality, UNESCO. Retrieved from http://www.unesco.org/new/filead min/MULTIMEDIA/HQ/BSP/GENDER/Working\%20 Paper_BriefingWorking\%2oPaper_S\%2oBassiuoni _Situation\%20of\%2oWomen\%2oin\%2oCentral\%2 oAsia.pdf)

Bar-Tal, Daniel 2009. "Reconciliation as a Foundation of Culture of Peace." In Handbook on Building Cultures of Peace, edited by Joseph de Rivera, 63-377. Springer: New York. 63.

Basu, Srimati 2012. "Judges of Normality: Mediating Marriage in the Family Courts of Kolkata, India." Signs 37(2):469-492.

Bogran, Michele 1999."Strengthening Domestic Violence Theories: Intersections of Race, Class, Sexual Orientation, and Gender." Journal of Marital and Family Therapy 25(3):275-289.

Btoush, Rula and Muhammed Haj-Yahia 2008 "Attitudes of Jordanian Society toward Wife Abuse." Journal of Interpersonal Violence 23(11):1531-1554.

Bui, Hoan and Merry Morach 1999. "Domestic Violence in the Vietnamese Immigrant Community: An Exploratory Study." Violence Against Women 5(7):769-795.

Chewter, Cynthia 2003. "Violence Against Women and Children: Some Legal Issues." Canadian Journal of Family Law, Spring 20(1):99-178.

Coker, Donna 2002 "Transformative Justice: AntiSubordination Processes in Cases of Domestic Violence." In Restorative Justice and Family Violence, edited by Heather Strang and John Braithwaite,128-152. Cambridge: University Press.
Cole, Elizabeth and Natalie Sabik 2009 "Repairing a Broken Mirror. Intersectional Approaches to Diverse Women's Perceptions of Beauty and Bodies." In The Intersectional Approach: Transforming the Academy Through Race, Class, and Gender, edited by Michele Tracy Berger and Kathleen Guidroz, 173-192. Chapel Hill: The University of North Carolina Press.

Committee on the Legal Statistics and Special Accounts of the State Office of Public Prosecutor of Republic of Kazakhstan 2012. Information Service. Electronic document, http://service.pravstat.kz/portal/page/portal/POPa geGroup/Services/Pravstat?_piref36_223083_36_2 23082_223082._ora_navigState=page\%3Dmode_ crime\&_piref36_223083_36_223082_223082._ora _navigValues=, accessed February 23, 2017

Devries, Karen, Joelle Mak, Claudia García-Moreno, Max Petzold, Jennifer Child, Gail Falder, Stephen Lim, Loraine Bacchus, Rebecca Engell, Lisa Rosenfeld, Christina Palitto, Theo Vos, N. Abrahams, and Charlotte Watts 2013." The Global Prevalence of Intimate Partner Violence Against Women." Science 340(6140):1527-1528.

Dhami, Sangeeta 2000. "The Muslim Family: Predicament and Promise." Journal of Culture and Medicine 173(1):352-356.

Doi, Abdur Rahman 1984 Shar'iah: The Islamic Law. London: Ta Ha.

Goodwin, Julia 2007. Breaking Down Barriers: Music and the Culture of Reconciliation in West Berlin, 19611989. Ph.D. dissertation, Department of History, University of Rochester

Hassler, Robin S. 1995. "Domestic Violence and the Politics of a Statewide Community." Women's Health Issues 5(4):199-202.

Hassouneh-Phillips, Dena Saadat 2001 "'Marriage is Half of Faith and the Rest is Fear Allah": Marriage and Spousal Abuse Among American Muslims." Violence Against Women 7(8):927-946.

Human Rights Council 2010. Report of the Working Group on the Universal Periodic Review: Kazakhstan. 
Kimmel, Michael 2002. " "Gender Symmetry" in Domestic Violence A Substantive and Methodological Research Review." Violence Against Women 8(11):1332-1363.

Kohn, Laurie S. 2010. "What's So Funny About Peace, Love, and Understanding? Restorative Justice as a New Paradigm for Domestic Violence Intervention." Seton Hall Law Review 40(2):517-595.

Koss, Mary 2000. "Blame, Shame, and Community: Justice Responses to Violence Against Women." American Psychologist 55(11):1332-1343.

Lazarus-Black, Mindie 2008. "Vanishing Complainants: The Place of Violence in Family, Gender, Work, and Law." Caribbean Studies 36(1):25-51.

Lazarus-Black, Mindie 2001. "Law and the Pragmatics of Inclusion: Governing Domestic Violence in Trinidad and Tobago." American Ethnologist 28(2):388-416.

London, Scott 1997. "Conciliation and Domestic Violence in Senegal, West Africa." PoLAR: Political and Legal Anthropology Review 20(2):83-91.

Joshi, Manisha, and Saltanat Childress 2017. "A national survey of attitudes toward intimate partner violence among married women in Kazakhstan, Kyrgyzstan, and Tajikistan: Implications for health prevention and intervention." Social Work in Health Care: 1-26.

Mann, Susan 2000. "The Scholarship of Difference: A Scholarship of Liberation?" Sociological Inquiry $70(4): 475-498$.

Mann, Susan and Michael Grimes 2001. "Common and Contested Ground: Marxism and Race, Gender, \& Class Analysis." Race, Gender, \& Class 8(2):3-22.

National Commission on Gender, Family and Demography Policy 2016 . Unpublished Draft: Family and Gender Concept of the Republic of Kazakhstan until 2030.

Nevada Attorney General 2011. Nevada Domestic Violence Resource Manual. Electronic document,http://ag.nv.gov/uploadedFiles/agnvgov /Content/Hot_Topics/Victims/DomesticViolenceRe sourceManual.pdf, accessed February 10, 2017.
Pattavina, April, David Hirschel, Eve Buzawa, Don Faggiani, and Helen Bentley 2007."A Comparison of the Police Response to Heterosexual Versus Same-Sex Intimate Partner Violence." Violence Against Women 13(4):374-394.

Rennison, Callie and Mike Planty 2003. "Nonlethal Intimate Partner Violence: Examining Race, Gender, and Income Patterns." Violence and Victims 18(4):433443 .

Richie, Beth 2000 "A Black Feminist Reflection on the Antiviolence Movement." Signs 25(4):1133-1137.

Ricoeur, Paul 1999 "Memory and Forgetting." In Questioning Ethics: Contemporary Debates in Philosophy, edited by Richard Kearney and Mark Dooley, 5-11. London: Routledge.

Rimelspach, Rene 2001. "Mediating Family Disputes in a World with Domestic Violence: How to Devise a Safe and Effective Court-Connected Mediation Program."Ohio State Journal on Dispute Resolution 17(1):95-112.

Rohrbaugh, Joanna 2006. "Domestic Violence in SameGender Relationships." Family Court Review 44(2): 287-299.

Schuler, Sidney, Rachel Lenzie, Tu-Anh Hoang, Song-Ha Vu, Kathryn Yount, and Quach Thu Trang 2014. "Recourse Seeking and Intervention in the Context of Intimate Partner Violence in Vietnam: A Qualitative Study." Journal of Family Issues 37(8): 1151-1173.

Snajdr, Edward 2005. "Gender, Power, and the Performance of Justice: Muslim Women's Responses to Domestic Violence in Kazakhstan." American Ethnologist 32(2):294-311.

Snajdr, Edward 2007. "Ethnicizing the subject: domestic violence and the politics of primordialism in Kazakhstan." Journal of the Royal Anthropological Institute 13(3): 603-620.

Snajdr, Edward 2010. "Balancing Acts: Women's NGOs Combating Domestic Violence in Kazakhstan." In Domestic Violence in Post-Communist States: Local Activism, National Policies, and Global Forces, edited by Fa Katalin, 111-132. Indiana University Press: Bloomington. 
Snell-Rood, Claire 2015. "Informal Support for Women and Intimate Partner Violence: The Crucial Yet Ambivalent Role of Neighbours in Urban India." Culture, Health \& Sexuality 17(1):63-77.

The Advocates for Human Rights 2010. Violence Against Women in Kazakhstan. Electronic document, http://www.stopvaw.org/kazakhstan, accessed February 22, 2017.

Tolman, Richard and Jodie Raphael 2000. "A Review of Research on Welfare and Domestic Violence." Journal of Social Issues 56(4):655-682.

UNIFEM 2005 . Kazakhstan: Crisis Centers Implement Higher Professional Standards to Responding to Violence against Women. Electronic document, www.unifem.org/gender_issues/voices_from_the_ field/story.php, accessed February 22, 2017.

United Nations 1993. Declaration on the Elimination of Violence Against Women A/RES/48/104 85th Plenary Meeting: December 20

UN Human Rights Council 2010. Report of the Working Group on the Universal Periodic Review: Kazakhstan. Geneva, Switzerland: Office of the United Nations High Commissioner for Human Rights.

U.S. Department of State 2007. Bureau of Democracy, Human Rights, and Labor: Kazakhstan. Electronic document, https://www.state.gov/j/drl/rls/hrrpt/2007/100615.h tm, accessed February 22, 2017.

West, Carolyn 2004. "Black Women and Intimate Partner Violence: New Directions for Research." Journal of Interpersonal Violence 19(12):1487-1493.

Carolyn West 2005. "Domestic Violence in Ethnically and Racially Diverse Families." In. Domestic Violence at the Margins: Readings on Race, Class, Gender, and Culture, edited by Natalie Sokoloff and Christina Pratt, 157-173. Rutgers University Press: New Jersey

Wies, Jennifer R. 2011."Anti-Domestic Violence Coalition Practice: Theorizing Collaboration and Participation." Annals of Anthropological Practice 35(2):66-78. 